\title{
Peanut Sensitivity and Allergic Rhinitis in Young Children are Associated with Attention-Deficit Hyperactivity Disorder Symptoms in Adolescence
}

This article was published in the following Dove Press journal: Neuropsychiatric Disease and Treatment

\author{
Mindy Ming-Huey Guo' \\ Liang-Jen Wang $\mathbb{( D}^{2}$ \\ Te-Yao $\mathrm{Hsu}^{3}$ \\ Kuender D Yang (iD ${ }^{4,5}$ \\ Ho-Chang Kuo (ID) \\ 'Department of Pediatrics, Kaohsiung \\ Chang Gung Memorial Hospital and \\ Chang Gung University College of \\ Medicine, Kaohsiung City, Taiwan; \\ ${ }^{2}$ Department of Child and Adolescent \\ Psychiatry, Kaohsiung Chang Gung \\ Memorial Hospital and Chang Gung \\ University College of Medicine, \\ Kaohsiung City, Taiwan; ${ }^{3}$ Department of \\ Obstetrics, Kaohsiung Chang Gung \\ Memorial Hospital and Chang Gung \\ University College of Medicine, \\ Kaohsiung City, Taiwan; ${ }^{4}$ Department of \\ Pediatrics and Department of Medical \\ Research, MacKay Memorial Hospital, \\ Taipei, Taiwan; ${ }^{5}$ Institute of Biomedical \\ Sciences, Mackay Medical School, Taipei, \\ Taiwan
}

Objective: Although childhood allergic diseases have been found to be associated with symptoms of attention-deficit hyperactivity disorder, the temporal relationship between these diseases remains unclear. In this study of 97 children, clinical examination and blood samples for total and specific IgE were collected at 6 and 12 years old.

Patients and Methods: We followed a total of 97 children from 6 to 12 years old. Clinical examination and blood samples for total and specific IgE were collected at 6 and 12 years old. Attention-deficit hyperactivity disorder and oppositional defiant disorder symptoms at 12 years old were evaluated using the Swanson, Nolan, and Pelham, Version IV Scale Parent Form.

Results: After accounting for the affect of confounding variables, we found that allergic rhinitis at 6 years old was associated with higher inattention score at 12 years old ( $\beta$-coefficient $0.356,95 \%$ CI $0.104-0.609, p=0.006$ ). In addition, higher specific IgE levels for peanuts at 6 years of age were correlated with higher hyperactivity/impulsivity scores ( $\beta$-coefficient $0.088,95 \%$ CI $0.049-0.126$, $\mathrm{p}<0.001$ ), and higher specific IgE for peanuts at 12 years of age were correlated with higher opposition/defiance scores ( $\beta$-coefficient $0.054,95 \%$ CI $0.012-0.096, \mathrm{p}=0.012$ ) at 12 years old in our final linear regression models.

Conclusion: Allergic rhinitis and peanut sensitization in childhood may be associated with more symptoms of attention-deficit hyperactivity and oppositional defiant disorder in adolescence.

Keywords: allergic disease, attention deficit hyperactivity disorder, oppositional defiant disorder

\section{Introduction}

Allergic diseases, such as atopic dermatitis, allergic rhinitis and asthma, are among the most common chronic diseases in childhood. According to population-based studies in the past three decades, the prevalence of allergic disease has increased particularly in developed countries, ${ }^{1}$ thus resulting in increased medical care costs in childhood, and loss of productivity in adulthood. ${ }^{2}$ As an example, in Taiwan where almost all children are covered by the National Health Insurance, health-care costs incurred by children with asthma were 2.2-fold higher overall when compared with children without asthma. ${ }^{3}$ The economic implications of allergic disease in adulthood is also considerable. In a study using widely publicized statistical data collected by the European Union, economic losses caused by lost productivity and absence from work is estimated to be 2405
Department of Pediatrics and

Department of Medical Research, MacKay

Memorial Hospital, Taipei No. 92, Sec. 2,

Zhongshan North. Road, Zhongshan

District, Taipei City, Taiwan

Email yangkd.yeh@gmail.com

Ho-Chang Kuo

Department of Pediatrics and Kawasaki

Disease Center, Kaohsiung Chang Gung

Memorial Hospital, I23 Da-Pei Road,

Niaosong District, Kaohsiung 8330I,

Taiwan

Tel $+8867731-7 \mid 23$ ext. 8795

Fax +886 733-8009

Email erickuo48@yahoo.com.tw 
euros per patient per year. ${ }^{4}$ While the economic burden of allergic disease is clear, ${ }^{4}$ less is known about the its impact on the psychological health of patients. Recent studies have shown that allergic diseases in children may be related to increased rates of anxiety, stress and attention-deficit hyperactivity disorder (ADHD) ${ }^{5}$

Attention-deficit hyperactivity disorder (ADHD) is a common neuropsychiatric disease that manifests during childhood and has an estimated prevalence rate of around $7.2 \%{ }^{6}$ According to the consensus criteria published in the Diagnostic and Statistical Manual of Mental Disorders Fifth Edition (DSM-5), children must have over 6 symptoms of hyperactivity, impulsivity or inattention to be diagnosed with ADHD. Moreover, these symptoms must be frequent, excessive for developmental age, occur in more than one setting (eg, at school and at home), persist for at least 6 months or more, severe enough to impair academic or social performance, and must present prior to 12 years of age. $^{7}$

Even though several large population studies have found a positive correlation between allergic disease and ADHD, ${ }^{8-10}$ such studies are cross-sectional, and thus cannot be applied to determine the temporal relationship between ADHD and allergic disease. In a meta-analysis of three case control studies and two cross-sectional studies that were conducted Taiwan, Germany, the United Kingdom (UK), Korea, and Thailand found that patients with ADHD were more likely to have asthma, allergic rhinitis or atopic dermatitis. ${ }^{11}$ However, the underlying pathophysiological link between allergic disease and ADHD is unknown. One possible hypothesis posits that chronic exposure to allergy-related inflammatory cytokines may alter the development of the prefrontal cortex, or affect the metabolism of important neurotransmitters in the brain. ${ }^{12}$ Functional MRI studies in patients with asthma show a positive correlation between markers for allergic inflammation such as sputum eosinophils and peripheral blood cell TNF- $\alpha$ production and increased activity in the anterior cingulate cortex and insula. ${ }^{13}$ Animal studies have also shown that inflammatory cytokines such as IL- 6 and IFN- $\gamma$ may increase production of norepinephrine and decrease dopamine levels, a neurotransmitter profile that can also be seen in patients with ADHD. ${ }^{12}$ Given that early childhood is a crucial time for neurodevelopment, it is plausible that onset of allergic diseases earlier in life may pose a larger risk for ADHD development. Therefore, more longitudinal studies are needed to determine if there is a temporal relationship between allergic disease in early childhood and the development of ADHD later in life.

In addition, whether the existence of allergic disease affects the severity of symptoms of ADHD is also an issue that has not been adequately explored in current literature. There is some evidence that the presence of allergic disease increases symptoms of ADHD in both children with and without comorbid ADHD. In a study of 333 children with allergic rhinitis and 332 healthy controls, allergic rhinitis was associated with higher scores related with inattention and emotional instability when rated using the Child Behavior Checklist. ${ }^{14}$ In another study that compared children with ADHD and comorbid asthma and those with ADHD alone, asthma comorbidity lead to increased symptoms of hyperactivity and impulsivity. ${ }^{15}$ Current treatment of ADHD relies on heavily on behavior modification and used of medications, most commonly stimulants such as methylphenidate. It is possible that control of comorbid allergic disease or avoidance of inciting allergens may also be effective adjunctive therapy. Consequently, further research that identifies allergic diseases and allergens that may intensify symptoms of ADHD may have useful therapeutic implications.

In this study, we used data from our allergic disease birth cohort of children who were recruited at birth and followed to 12 years of age to achieve the following aims: 1. To identify the temporal relationship between age of allergic disease or allergen sensitization onset and symptoms of ADHD. 2. To identify the allergic diseases and specific allergens most likely to contribute to increased severity of ADHD symptoms.

\section{Patients and Methods}

Patients included in our study had been previously enrolled in our allergic disease birth cohort study. ${ }^{16-18}$ According to our study protocol, patients were recruited at birth and followed at our allergy clinic at 6 and 12 years old. The following data were collected at birth: Gender, prenatal exposure to smoking and gestational age. Prematurity was defined as a gestational age of less than 37 weeks at birth.

Patients were then followed at our allergy clinic at two time points: 6 and 12 years old. Clinic visits included an evaluation of allergic symptoms using a modified version of the International Study of Asthma and Allergies in Childhood (ISAAC) questionnaire ${ }^{19}$ and physician evaluation of asthma, atopic dermatitis, and allergic rhinitis. Diagnosis of asthma, atopic dermatitis and allergic rhinitis 
were determined by presence of active symptoms within the past year. Patients were diagnosed with atopic dermatitis if they fulfilled the at least three of the major HanifinRajka criteria for atopic dermatitis: pruritis, chronic relapsing dermatitis, characteristic morphological distribution, and personal or family history of atopic dermatitis. ${ }^{20}$ A clinical diagnosis of allergic rhinitis was made if the patient had recurrent nasal symptoms including rhinorrhea, nasal congestion, sneezing, or itching of the nose without other symptoms of upper respiratory infection for more than four days a week persisting for at least two weeks or more within the past year. ${ }^{21}$ A clinical diagnosis of active asthma was made if the patient had symptoms of persistent coughing particularly at night or when waking, increased coughing and wheezing induced by exercise, cold air, allergens or viral infections, or if the patient had at least one episode of wheezing requiring inhaled bronchodilators or inhaled or systemic steroids within the past year. ${ }^{22}$ Blood samples were also obtained at 6 years and 12 years old and were sent for serum analysis of total and specific IgE levels for D. pteronyssinus, cockroach, milk, egg white, peanut and shrimp using the Pharmacia CAP system (Pharmacia \& Upjohn DiagnosticAB, Uppsala, Sweden). An initial pilot study of 100 random samples was used to identify the four most common allergens in the general population: Dermatophagoides pteronyssinus (35.0\%), cockroach $(17.6 \%)$, shrimp (14.6\%), and peanut $(7 \%){ }^{23}$ We also included milk protein and egg white, two of the most common food allergens observed in Asian children in our testing panel. ${ }^{24}$

We mailed all the patients enrolled in our birth cohort study who returned for the 12-year-old follow-up visit, the Chinese version of the Swanson, Nolan, and Pelham, version IV scale - Parent Form (SNAP-IV). Previous studies have demonstrated that the Chinese version of the SNAP-IV Parent Form is a reliable and psychometrically valid screening tool for ADHD and ODD in Taiwan. In a cohort of 3534 schoolchildren, the Chinese version of SNAP-IV had a high degree of test-retest reliability and was highly correlated to other scoring systems designed to test for symptoms and behaviors related to ADHD including SDQ (Strengths and Difficulties Questionnaire) and CBCL (Child Behavior Checklist). ${ }^{25}$ The 26 questions in the SNAP-IV Parent Form were scored on a 4 point scale $(0=$ not at all, $1=$ just a little, $2=$ quite a bit and $3=\mathrm{a}$ lot), and an average score per question was calculated for the three subsets of symptoms: inattention (questions 1-9), hyperactivity/impulsivity (questions 10-18) and opposition/defiance (questions 19-26). Children who scored above the 95th percentile for each subset (1.78 for inattention, 1.44 for hyperactivity/impulsivity and 1.88 for opposition/defiance) were considered to be at high risk for ADHD or oppositional defiant disorder. ${ }^{26}$ Medical chart review was also performed to identify patients who have received a diagnosis of neuropsychiatric disease including tic disorder, Tourette's syndrome, epilepsy or autism.

We performed Statistical analysis using SPSS for Windows, version 19.0 (SPSS Inc., Chicago, IL, USA). Differences in the SNAP-IV Parent Form average score per question were compared using Student's $t$-test, and Pearson's correlation was applied to identify the relationship between total and specific IgE levels with the SNAP-IV Parent Form average score per question for all three subsets. Finally, factors with a p-value of less than 0.05 on univariate analysis were selected for multivariate analysis to obtain a final linear regression model.

Our study protocol was approved by the Internal Review Board of Chang Gung Memorial Hospital (IRB number: 102-2895B) and written informed consent was obtained from the parents or guardians of all the patients in this study. All experiments and data collection were performed in accordance with the guidelines and regulations outlined by the Internal Review Board of Chang Gung Memorial Hospital.

\section{Results}

\section{Demographic Data}

Of the 207 children enrolled in our birth cohort study who came to their follow-up appointment at 12 years old, 97 of those children's parents agreed to complete the SNAP-IV Parent Form. Among them, 53 respondents were male $(54.6 \%), 6$ had a gestational age of less than 37 weeks at birth $(6.1 \%)$, and 5 had prenatal exposure to smoking (5.1\%). The prevalence of asthma, allergic rhinitis and atopic dermatitis at six years old was $24.2 \%, 63.2 \%$ and $14.7 \%$, respectively. The prevalence of asthma, allergic rhinitis and atopic dermatitis at 12 years old was 5.3\%, 72.9\% and $21.8 \%$, respectively. The percentage of patients that scored above the 95th percentile on the SNAP-IV Parent Form for inattention, hyperactivity/impulsivity and opposition/defiance at 12 years old was $2.1 \%, 2.1 \%$ and $4.1 \%$, respectively. A medical chart review was also performed and identified 
five patients who received a neuropsychiatric diagnosis within the study period: two patients with tic disorder, one patient with Tourette's syndrome, one with autism and one with epilepsy. None of the patients in our study had a history of developmental delay or head trauma.

\section{Comparison SNAP-IV Parent Form Scores at 12 Years Old in Patients with and Without Allergic Disease}

Patients who had asthma or allergic rhinitis at six years old had higher SNAP-IV Parent Form scores for inattention at 12 years old $(0.83 \pm 0.12$ vs $0.58 \pm 0.05$, $p=0.041$ and $0.76 \pm 0.07$ vs $0.46 \pm 0.07, p=0.005$, respectively). Furthermore, patients with allergic rhinitis at six years old also had higher scores for opposition/ defiance at 12 years old $(0.74 \pm 0.07$ vs $0.48 \pm 0.07$, $p=0.013)$. On the other hand, patients with atopic dermatitis at six years old did not have significantly different SNAP-IV Parent Form scores at 12 years old when compared to those without. Active asthma, allergic rhinitis and atopic dermatitis at 12 years old were not associated with significant differences in SNAP-IV Parent Form scores at 12 years old (Table 1).

\section{Univariate Analysis of Total and Specific IgE Levels with SNAP-IV Parent Form Scores at 12 Years Old}

We found a positive correlation among all three subsets of SNAP-IV Parent Form scores at 12 years old and peanutspecific IgE levels at both 6 and 12 years old (Pearson's correlation for inattention $0.323, p=0.001$ and $0.347, p=0.001$, hyperactivity/impulsivity $0.413, p<0.001$ and 0.390 , $p<0.001$, opposition/defiance $0.267, p=0.009$ and 0.265 , $p=0.009$ at 6 years old and 12 years old, respectively). Higher hyperactivity/impulsivity scores at 12 years old were positively correlated with higher specific IgE levels for cockroaches at six years old (Pearson's correlation 0.236, $p=0.022$ ). Meanwhile, higher inattention scores at 12 years old were positively correlated with higher specific IgE levels for shrimp at 12 years old (Pearson's correlation 0.269, $p=0.008)$ (Table 2).

\section{Linear Regression of Factors Associated with SNAP-IV Parent Form Scores}

After univariate analysis, factors that had a statistically significant effect on SNAP-IV scores on univariate analysis (ie,

Table I Comparison of SNAP-IV Parent Form Scores in 12-Year-Old Patients with and Without Allergic Disease

\begin{tabular}{|c|c|c|c|c|c|c|}
\hline & $\begin{array}{l}\text { Inattention } \\
\text { Score* } \\
\text { (Mean } \pm \text { SE) }\end{array}$ & $p$-value & 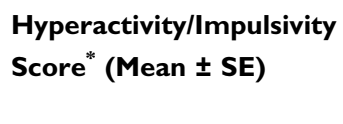 & $p$-value & $\begin{array}{l}\text { Opposition/Defiance } \\
\text { Score }^{*} \text { (Mean } \pm \text { SE) }\end{array}$ & $p$-value \\
\hline $\begin{array}{l}6 \text { y/o asthma } \\
\text { No }(\mathrm{N}=72) \\
\text { Yes }(\mathrm{N}=23)\end{array}$ & $\begin{array}{l}0.58 \pm 0.05 \\
0.83 \pm 0.12\end{array}$ & 0.041 & $\begin{array}{l}0.20 \pm 0.03 \\
0.43 \pm 0.11\end{array}$ & 0.062 & $\begin{array}{l}0.60 \pm 0.06 \\
0.79 \pm 0.13\end{array}$ & 0.144 \\
\hline $\begin{array}{l}6 \text { y/o allergic rhinitis } \\
\text { No }(\mathrm{N}=35) \\
\text { Yes }(\mathrm{N}=60)\end{array}$ & $\begin{array}{l}0.46 \pm 0.07 \\
0.76 \pm 0.07\end{array}$ & 0.005 & $\begin{array}{l}0.17 \pm 0.04 \\
0.30 \pm 0.05\end{array}$ & 0.093 & $\begin{array}{l}0.48 \pm 0.07 \\
0.74 \pm 0.07\end{array}$ & 0.013 \\
\hline $\begin{array}{l}6 \text { y/o atopic dermatitis } \\
\text { No }(N=8 I) \\
\text { Yes }(N=14)\end{array}$ & $\begin{array}{l}0.65 \pm 0.06 \\
0.61 \pm 0.14\end{array}$ & 0.782 & $\begin{array}{l}0.26 \pm 0.04 \\
0.23 \pm 0.12\end{array}$ & 0.780 & $\begin{array}{l}0.64 \pm 0.06 \\
0.67 \pm 0.15\end{array}$ & 0.859 \\
\hline $\begin{array}{l}12 \text { y/o asthma } \\
\text { No }(\mathrm{N}=89) \\
\text { Yes }(\mathrm{N}=5)\end{array}$ & $\begin{array}{l}0.66 \pm 0.05 \\
0.71 \pm 0.20\end{array}$ & 0.833 & $\begin{array}{l}0.27 \pm 0.04 \\
0.18 \pm 0.09\end{array}$ & 0.582 & $\begin{array}{l}0.69 \pm 0.06 \\
0.48 \pm 0.15\end{array}$ & 0.391 \\
\hline $\begin{array}{l}12 \text { y/o allergic rhinitis } \\
\text { No }(N=26) \\
\text { Yes }(N=70)\end{array}$ & $\begin{array}{l}0.57 \pm 0.09 \\
0.69 \pm 0.06\end{array}$ & 0.295 & $\begin{array}{l}0.21 \pm 0.06 \\
0.28 \pm 0.05\end{array}$ & 0.387 & $\begin{array}{l}0.55 \pm 0.09 \\
0.72 \pm 0.68\end{array}$ & 0.178 \\
\hline $\begin{array}{l}12 \text { y/o atopic dermatitis } \\
\text { No }(\mathrm{N}=68) \\
\text { Yes }(\mathrm{N}=19)\end{array}$ & $\begin{array}{l}0.64 \pm 0.06 \\
0.68 \pm 0.12\end{array}$ & 0.697 & $\begin{array}{l}0.22 \pm 0.03 \\
0.35 \pm 0.10\end{array}$ & 0.127 & $\begin{array}{l}0.65 \pm 0.07 \\
0.66 \pm 0.14\end{array}$ & 0.929 \\
\hline
\end{tabular}

Note: *Average score per question. 
Table 2 Correlation Between Total IgE, Specific IgE Levels and SNAP-IV Parent Form Scores in I2-year-Olds

\begin{tabular}{|c|c|c|c|c|c|c|}
\hline & $\begin{array}{l}\text { Inattention Score* } \\
\text { (Pearson's } \\
\text { Correlation) }\end{array}$ & $p$-value & $\begin{array}{l}\text { Hyperactivityl } \\
\text { Impulsivity } \\
\text { Score* (Pearson's } \\
\text { Correlation) }\end{array}$ & $p$-value & $\begin{array}{l}\text { Opposition/ } \\
\text { Defiance Score } \\
\text { (Pearson's } \\
\text { Correlation) }\end{array}$ & $p$-value \\
\hline 6 y/o Total lgE & 0.041 & 0.696 & -0.038 & 0.715 & 0.006 & 0.954 \\
\hline \multicolumn{7}{|l|}{6 y/o Specific lgE } \\
\hline Mite & -0.790 & 0.445 & -0.175 & 0.090 & -0.098 & 0.345 \\
\hline Cockroach & 0.156 & 0.130 & 0.236 & 0.022 & 0.117 & 0.261 \\
\hline Egg & -0.025 & 0.810 & -0.041 & 0.691 & 0.020 & 0.845 \\
\hline Milk & -0.002 & 0.983 & -0.031 & 0.769 & 0.118 & 0.225 \\
\hline Peanut & 0.323 & 0.001 & 0.413 & $<0.001$ & 0.267 & 0.009 \\
\hline Shrimp & 0.207 & 0.044 & 0.221 & 0.032 & 0.145 & 0.162 \\
\hline 12 y/o Total lgE & 0.061 & 0.552 & -0.131 & 0.199 & 0.158 & 0.122 \\
\hline \multicolumn{7}{|l|}{12 y/o Specific lgE } \\
\hline Mite & -0.126 & 0.217 & -0.231 & 0.023 & -0.153 & 0.134 \\
\hline Cockroach & 0.195 & 0.056 & 0.122 & 0.233 & 0.099 & 0.333 \\
\hline Egg & -0.170 & 0.870 & -0.169 & 0.099 & $0.07 I$ & 0.491 \\
\hline Milk & -0.060 & $0.56 \mathrm{I}$ & -0.165 & 0.107 & 0.041 & 0.691 \\
\hline Peanut & 0.347 & 0.001 & 0.390 & $<0.001$ & 0.265 & 0.009 \\
\hline Shrimp & 0.269 & 0.008 & 0.136 & 0.183 & 0.156 & 0.127 \\
\hline
\end{tabular}

Note: *Average score per question.

a $p$-value of less than 0.05) were included in our multivariate linear regression models for inattention, hyperactivity/impulsivity and opposition/defiance. Confounding factors for ADHD including male gender, ${ }^{27}$ history of neuropsychiatric disease (tic syndrome, Tourette's disease, epilepsy and autism), prematurity ${ }^{28}$ and prenatal exposure to smoking ${ }^{29}$ were also included in the linear regression model for each of the three scores. However, because there was a very high degree of collinearity between specific $\mathrm{IgE}$ levels for peanut and shrimp at 6 years old and specific IgE levels for peanut and shrimp at 12 years old, we ran two linear regression models for each SNAP-IV score: one with specific IgE levels at 6 years old and another with specific IgE levels at 12 years old, and selected the linear regression model with the highest $\mathrm{R}$-squared value. Results of our final linear regression model for each SNAP-IV score can be seen in Table 3. After accounting for the affect confounding variables including male gender, history of neuropsychiatric disease, prenatal exposure to smoking and prematurity, we found that allergic rhinitis at 6 years old still had a statistically significant effect on inattention scores at 12 years old ( $\beta$-coefficient 0.356 , 95\% CI 0.104-0.609, $p=0.006$ ). In addition, higher specific $\mathrm{IgE}$ levels for peanuts at 6 years of age were correlated with higher hyperactivity/impulsivity scores $(\beta$-coefficient 0.088 , 95\% CI $0.049-0.126, p<0.001$ ), and higher specific
$\operatorname{IgE}$ for peanuts at 12 years of age were correlated with higher opposition/defiance scores ( $\beta$-coefficient $0.088,95 \%$ CI $0.049-0.126, p<0.001)$ at 12 years old in our final linear regression models (Table 3 ).

\section{Discussion}

In our longitudinal birth cohort study, we found that of the three major allergic diseases (asthma, atopic dermatitis and allergic rhinitis) only active allergic rhinitis at the 6-yearold clinic visit was associated with higher SNAP-IV Parent Form scores taken 6 years later when the subjects were 12 years old. Of particular note, patients who had active asthma, atopic dermatitis or allergic rhinitis at the 12-year-old clinic visit did not have higher SNAP-IV scores for ADHD and ODD. While previous research has found a link between the presence of allergic disease and ADHD, $, 9,10,30$ the majority of such studies have been crosssectional in nature. In continuing our original birth cohort study, we were able to examine the longitudinal effect of allergic disease on ADHD and ODD symptoms. After linear regression analysis which included possible confounding factors such as male gender, history of neuropsychiatric disease, prematurity and prenatal exposure to smoking, we found that of the six allergens tested, only peanut allergen sensitivity remained statistically 
Table 3 Factors Affecting SNAP-IV Parent Form Scores After Linear Regression

\begin{tabular}{|c|c|c|c|c|}
\hline Model for Inattention Score & $\beta$-Coefficient & 95\% Confidence Interval for $\beta$-Coefficient & Standard Error & p-value \\
\hline Male gender & -0.204 & $-0.448-0.040$ & 0.123 & 0.099 \\
\hline Neuropsychiatric disease ${ }^{*}$ & 0.695 & $0.153-1.237$ & 0.273 & 0.013 \\
\hline Prenatal exposure to smoking & 0.096 & $-0.166-0.357$ & 0.131 & 0.469 \\
\hline Prematurity & 0.089 & $-0.394-0.572$ & 0.243 & 0.716 \\
\hline Asthma at 6 y/o & 0.198 & $-0.092-0.487$ & 0.146 & 0.179 \\
\hline Allergic rhinitis at $6 \mathrm{y} / \mathrm{o}$ & 0.356 & $0.104-0.609$ & 0.127 & 0.006 \\
\hline Peanut specific $\lg E$ at $12 \mathrm{y} / \mathrm{o}$ & 0.035 & $-0.009-0.079$ & 0.022 & 0.120 \\
\hline Shrimp specific lgE at 12 y/o & 0.103 & $-0.024-0.229$ & 0.064 & 0.111 \\
\hline Model for Hyperactivity and Impulsivity score & $\beta$-Coefficient & 95\% Confidence Interval for $\beta$-Coefficient & Standard Error & $p$-value \\
\hline Male gender & 0.063 & $-0.101-0.227$ & 0.083 & 0.448 \\
\hline Neuropsychiatric disease ${ }^{*}$ & 0.521 & $0.148-0.894$ & 0.188 & 0.007 \\
\hline Prenatal exposure to smoking & -0.077 & $-0.254-0.099$ & 0.089 & 0.386 \\
\hline Prematurity & 0.196 & $-0.127-0.520$ & 0.163 & 0.231 \\
\hline Cockroach specific lgE at 6 y/o & -0.057 & $-0.202-0.088$ & 0.073 & 0.438 \\
\hline Peanut specific $\lg E$ at $6 y / o$ & 0.088 & $0.049-0.126$ & 0.019 & $<0.001$ \\
\hline Shrimp specific lgE at 6 y/o & -0.096 & $-0.246-0.053$ & 0.075 & 0.204 \\
\hline Model for Opposition and Defiance score & $\beta$-Coefficient & 95\% Confidence Interval for $\beta$-Coefficient & Standard Error & $p$-value \\
\hline Male gender & -0.236 & $-0.494-0.022$ & 0.130 & 0.072 \\
\hline Neuropsychiatric disease ${ }^{*}$ & 0.927 & $0.353-1.501$ & 0.289 & 0.002 \\
\hline Prenatal exposure to smoking & 0.074 & $-0.202-0.35$ I & 0.139 & 0.595 \\
\hline Prematurity & -0.068 & $-0.578-0.442$ & 0.257 & 0.792 \\
\hline Allergic rhinitis at 6 y/o & 0.247 & $-0.012-0.507$ & 0.131 & 0.062 \\
\hline Peanut specific lgE at 12 y/o & 0.054 & $0.012-0.096$ & 0.021 & 0.012 \\
\hline
\end{tabular}

Note: *Presence of either tic disorder, Tourette's syndrome, autism or epilepsy.

significant in our final linear regression model. While prior studies have demonstrated an association between ADHD and a history of food allergies, ${ }^{31,32}$ none have identified a clear link between ADHD symptoms and allergenspecific serum IgE. As far as we know, this study is the first to describe an association between peanut allergen sensitivity and ADHD and ODD symptoms.

After reviewing the current literature, we discovered only two longitudinal studies that focused on the temporal relationship between the age of allergic disease onset and the subsequent development of ADHD symptoms. In one large longitudinal study of children who were followed for 10 years, children with a history of atopic disease (including asthma, allergic rhinitis, atopic dermatitis and allergic conjunctivitis) prior to the age of three years were at a higher risk of developing ADHD when older. ${ }^{33}$ Likewise, in a birth cohort study of 2916 children, those with infantile atopic dermatitis had the highest risk of hyperactivity and inattention at 10 years old when compared with children with atopic dermatitis after 3 years old. ${ }^{34}$ In this study, we found that allergic rhinitis at 6 years old still had a statistically significant effect on symptoms of ADHD at 12 years old even after possible confounding factors such as male gender, history of neuropsychiatric disease, prematurity and prenatal exposure to smoking were included in the linear regression model. While many genetic and environmental factors may affect the development of ADHD, our findings as well the results of the studies mentioned above suggest that allergic diseases in early childhood may be correlated with symptoms of ADHD later in life.

The relationship between specific food allergens and ADHD has not yet been well established. Although various cross-sectional studies have found patients with food allergies to be associated with a higher degree of general anxiety and ADHD symptoms, they were not associated with an increased risk of meeting diagnostic criteria for psychiatric diseases. ${ }^{31,32}$ However, none of these studies included food allergen-specific IgE levels in their analysis. Of the four food-related antigens that we included in our specific IgE panel, only an increased sensitivity to peanuts was found to have a correlation with increased ADHD symptoms after univariate and linear regression analysis. To the best of our knowledge, this appears to be a novel finding, although what role peanut sensitization may play in the development of ADHD is still unclear. 
While our results show that allergic disease in early childhood is associated with subsequent ADHD and ODD symptoms, the underlying mechanisms between allergic disease and neuropsychiatric health are still a matter of debate. One explanation suggests that allergic diseases may influence neuro-immunological pathways which may alter brain function and development. Inflammatory cytokines released during an allergic response can cross the blood-brain barrier ${ }^{35}$ and may activate the prefrontal cortex, which is associated with executive cognition, motivation and attention. ${ }^{13,36}$ Other explanations indicate that psychological stress and sleep disturbances associated with atopic disease may affect emotional and mental development, especially early in life during which there is a high degree of neural plasticity. ${ }^{37,38}$

The strengths of our research include our longitudinal study design. By using data originally obtained from our birth cohort study for allergic disease, we were able to examine the temporal relationship between allergic disease and ADHD. Furthermore, we included total and specific IgE data at both six and 12 years old, which is uncommon for studies of this nature. This study's limitations include our relatively small sample size. In addition, because ADHD is a complex multifactorial disease, it is difficult to account for all possible confounding factors that may contribute to symptoms of ADHD at 12 years of age. Likewise, although our allergen panel included the 6 most common allergens in a Taiwanese population, it is by no means comprehensive. Because evaluating ADHD symptoms in our cohort relied solely on parents' perspectives instead of an active survey or structural interview, the results of this study may have been affected by parental recall bias. In addition, only $2-4 \%$ of the participating patients had scores high enough to be consistent with an ADHD diagnosis, which is slightly lower than the incidence of ADHD reported in relevant literature. ${ }^{6}$ This finding may be due to the fact that ADHD symptoms typically decline in adolescents. Furthermore, the incidence of allergic disease in our subjects is higher than what is commonly reported, which may have been the result of patient self-selection bias. Since we only enrolled patients who had already been a part of our allergic disease birth cohort study, patients with a history of allergic disease may have been more likely to agree to further evaluation at 12 years of age.

In conclusion, in this longitudinal study of patients who were followed from birth to 12 years old we found that early onset allergic rhinitis and peanut allergen sensitivity at six years of age were associated with higher scores for SNAP-IV
Parent Form scores at 12 years old. Our findings suggest that the early onset of allergic disease and food allergen sensitization may be correlated to higher symptoms of ADHD and ODD symptoms in adolescence. Further research is necessary to determine the biological mechanisms involved.

\section{Acknowledgments}

We would like to thank the Biostatistics Center at Kaohsiung Chang Gung Memorial Hospital for their contributions to the statistical analysis of this study. The abstract of this paper was presented at 22nd Congress of the Asian Pacific Society of Respirology, held in Sydney, Australia, 23-26 November 2017 as a poster with interim findings. (https://onlinelibrary.wiley.com/toc/14401843/ $\underline{22 / S 3)}$

\section{Funding}

This work was supported by a grant from Chang Gung Memorial Hospital, Taiwan (CMRPG8D0551, CMRPG8C1082, CMRPG8B0212, CMRPG8D1561 and CMRPG8D0521, CLRPG8D0112, and CMRPG8D0032). This study was partly supported by a grant from the Ministry of Science and Technology, Taiwan (MOST 102-2314-B-182-053-MY3). The funders had no role in study design, data collection and analysis, decision to publish, or preparation of the manuscript.

\section{Disclosure}

The authors declare that no competing interests exist.

\section{References}

1. Worldwide variation in prevalence of symptoms of asthma, allergic rhinoconjunctivitis, and atopic eczema: ISAAC. The International Study of Asthma and Allergies in Childhood (ISAAC) steering committee. Lancet. 1998;351(9111):1225-1232.

2. Tai A, Tran H, Roberts M, et al. Outcomes of childhood asthma to the age of 50 years. J Allergy Clin Immunol. 2014;133(6):1572-1578 e1573. doi:10.1016/j.jaci.2013.12.1033

3. Sun HL, Kao YH, Lu TH, Chou MC, Lue KH. Health-care utilization and costs in Taiwanese pediatric patients with asthma. Pediatr Int. 2007;49(1):48-52. doi:10.1111/j.1442-200X.2007.02317.x

4. Zuberbier T, Lotvall J, Simoens S, Subramanian SV, Church MK. Economic burden of inadequate management of allergic diseases in the European Union: a GA(2) LEN review. Allergy. 2014;69 (10):1275-1279. doi:10.1111/all.12470

5. Garg N, Silverberg JI. Association between childhood allergic disease, psychological comorbidity, and injury requiring medical attention. Ann Allergy Asthma Immunol. 2014;112(6):525-532. doi:10.1016/j. anai.2014.03.006

6. Thomas R, Sanders S, Doust J, Beller E, Glasziou P. Prevalence of attention-deficit/hyperactivity disorder: a systematic review and meta-analysis. Pediatrics. 2015;135(4):e994-1001. doi:10.1542/ peds.2014-3482 
7. Doernberg E, Hollander E. Neurodevelopmental disorders (ASD and ADHD): DSM-5, ICD-10, and ICD-11. CNS Spectr. 2016;21 (4):295-299. doi:10.1017/S1092852916000262

8. Schmitt J, Romanos M, Schmitt NM, Meurer M, Kirch W. Atopic eczema and attention-deficit/hyperactivity disorder in a population-based sample of children and adolescents. JAMA. 2009;301(7):724-726. doi:10.1001/jama.2009.136

9. Tsai JD, Chang SN, Mou CH, Sung FC, Lue KH. Association between atopic diseases and attention-deficit/hyperactivity disorder in childhood: a population-based case-control study. Ann Epidemiol. 2013;23(4):185-188. doi:10.1016/j.annepidem.2012.12.015

10. Tsai MC, Lin HK, Lin CH, Fu LS. Prevalence of attention deficit/ hyperactivity disorder in pediatric allergic rhinitis: a nationwide population-based study. Allergy Asthma Proc. 2011;32(6):41-46. doi:10.2500/aap.2011.32.3489

11. Miyazaki C, Koyama M, Ota E, et al. Allergic diseases in children with attention deficit hyperactivity disorder: a systematic review and meta-analysis. BMC Psychiatry. 2017;17(1):120. doi:10.1186/ s12888-017-1281-7

12. Buske-Kirschbaum A, Schmitt J, Plessow F, Romanos M, Weidinger S, Roessner V. Psychoendocrine and psychoneuroimmunological mechanisms in the comorbidity of atopic eczema and attention deficit/hyperactivity disorder. Psychoneuroendocrinology. 2013;38(1):12-23. doi:10.1016/j.psyneuen.2012.09.017

13. Rosenkranz MA, Busse WW, Johnstone T, et al. Neural circuitry underlying the interaction between emotion and asthma symptom exacerbation. Proc Natl Acad Sci $U$ S A. 2005;102 (37):13319-13324. doi:10.1073/pnas.0504365102

14. Feng B, Jin H, Xiang H, et al. Association of pediatric allergic rhinitis with the ratings of attention-deficit/hyperactivity disorder. Am J Rhinol Allergy. 2017;31(3):161-167. doi:10.2500/ajra. 2017.31.4439

15. Borschuk AP, Rodweller C, Salorio CF. The influence of comorbid asthma on the severity of symptoms in children with attention-deficit hyperactivity disorder. J Asthma. 2018;55(1):66-72. doi:10.1080/ 02770903.2017.1306549

16. Yang $\mathrm{KD}$, Ou CY, Chang JC, et al. Infant frequent wheezing correlated to clara cell protein $10(\mathrm{CC} 10)$ polymorphism and concentration, but not allergy sensitization, in a perinatal cohort study. $J$ Allergy Clin Immunol. 2007;120(4):842-848. doi:10.1016/j. jaci.2007.07.009

17. Kuo HC, Liu CA, Ou CY, et al. Partial protein-hydrolyzed infant formula decreased food sensitization but not allergic diseases in a prospective birth cohort study. Int Arch Allergy Immunol. 2011;154(4):310-317. doi:10.1159/000321823

18. Guo MM, Tseng WN, Ou CY, Hsu TY, Kuo HC, Yang KD. Predictive factors of persistent infantile atopic dermatitis up to 6 years old in Taiwan: a prospective birth cohort study. Allergy. 2015;70(11):1477-1484. doi:10.1111/all.12706

19. Tsakok T, Weinmayr G, Jaensch A, Strachan DP, Williams HC, Flohr C. Eczema and indoor environment: lessons from the International Study of Asthma and Allergies in Childhood (ISAAC) phase 2. Lancet. 2015;385(Suppl 1):S99. doi:10.1016/S01406736(15)60414-7

20. Akan A, Dibek-Misirlioglu E, Civelek E, Vezir E, Kocabas CN. Diagnosis of atopic dermatitis in children: comparison of the Hanifin-Rajka and the United Kingdom working party criteria. Allergol Immunopathol (Madr). 2019.

21. Bousquet J, Khaltaev N, Cruz AA, et al. Allergic Rhinitis and its Impact on Asthma (ARIA) 2008 update (in collaboration with the World Health Organization, GA(2)LEN and AllerGen). Allergy. 2008;63(Suppl 86):8-160.
22. Bousquet J, Clark TJ, Hurd S, et al. GINA guidelines on asthma and beyond. Allergy. 2007;62(2):102-112. doi:10.1111/j.1398-9995. 2006.01305.x

23. Liu CA, Wang CL, Chuang H, Ou CY, Hsu TY, Yang KD. Prenatal prediction of infant atopy by maternal but not paternal total $\operatorname{IgE}$ levels. J Allergy Clin Immunol. 2003;112(5):899-904. doi:10.1016/j. jaci.2003.08.030

24. Lee AJ, Thalayasingam M, Lee BW. Food allergy in Asia: how does it compare? Asia Pac Allergy. 2013;3(1):3-14. doi:10.5415/ apallergy.2013.3.1.3

25. Gau SS, Shang CY, Liu SK, et al. Psychometric properties of the Chinese version of the Swanson, Nolan, and Pelham, version IV scale - parent form. Int J Methods Psychiatr Res. 2008;17(1):35-44. doi:10.1002/mpr.237

26. Liu YCLS, Shang CY, Lin CH, Tu CL, Gau SF. Norm of the Chinese version of the Swanson, Nolan and Pelham, version IV scale for ADHD. Taiwan J Psychiatry. 2006;20:15.

27. Xu G, Strathearn L, Liu B, Yang B, Bao W. Twenty-year trends in diagnosed attention-deficit/hyperactivity disorder among US children and adolescents, 1997-2016. JAMA Netw Open. 2018;1(4):e181471. doi:10.1001/jamanetworkopen.2018.1471

28. Lindstrom K, Lindblad F, Hjern A. Preterm birth and attention-deficit/hyperactivity disorder in schoolchildren. Pediatrics. 2011;127(5):858-865. doi:10.1542/peds.2010-1279

29. Huang L, Wang Y, Zhang L, et al. Maternal smoking and attention-deficit/hyperactivity disorder in offspring: a meta-analysis. Pediatrics. 2018;141(1):e20172465. doi:10.1542/peds.2017-2465

30. Schmitt J, Buske-Kirschbaum A, Roessner V. Is atopic disease a risk factor for attention-deficit/hyperactivity disorder? A systematic review. Allergy. 2010;65(12):1506-1524. doi:10.1111/j.13989995.2010.02449.x

31. Ferro MA, Van Lieshout RJ, Ohayon J, Scott JG. Emotional and behavioral problems in adolescents and young adults with food allergy. Allergy. 2016;71(4):532-540. doi:10.1111/all.12829

32. Shanahan L, Zucker N, Copeland WE, Costello EJ, Angold A. Are children and adolescents with food allergies at increased risk for psychopathology? J Psychosom Res. 2014;77(6):468-473. doi:10.1016/j.jpsychores.2014.10.005

33. Chen MH, Su TP, Chen YS, et al. Is atopy in early childhood a risk factor for ADHD and ASD? A longitudinal study. J Psychosom Res. 2014;77(4):316-321. doi:10.1016/j.jpsychores.2014.06.006

34. Schmitt J, Apfelbacher C, Chen CM, et al. Infant-onset eczema in relation to mental health problems at age 10 years: results from a prospective birth cohort study (German Infant Nutrition Intervention plus). J Allergy Clin Immunol. 2010;125(2):404-410. doi:10.1016/j.jaci.2009.10.055

35. Yarlagadda A, Alfson E, Clayton AH. The blood brain barrier and the role of cytokines in neuropsychiatry. Psychiatry (Edgmont). 2009;6 (11):18-22.

36. Goto Y, Yang CR, Otani S. Functional and dysfunctional synaptic plasticity in prefrontal cortex: roles in psychiatric disorders. Biol Psychiatry. 2010;67(3):199-207. doi:10.1016/j.biopsych.2009.08.026

37. Sanchez MM, Ladd CO, Plotsky PM. Early adverse experience as a developmental risk factor for later psychopathology: evidence from rodent and primate models. Dev Psychopathol. 2001;13(3):419-449. doi:10.1017/S0954579401003029

38. Ednick M, Cohen AP, McPhail GL, Beebe D, Simakajornboon N, Amin RS. A review of the effects of sleep during the first year of life on cognitive, psychomotor, and temperament development. Sleep. 2009;32(11):1449-1458. doi:10.1093/sleep/32.11.1449 


\section{Publish your work in this journal}

Neuropsychiatric Disease and Treatment is an international, peerreviewed journal of clinical therapeutics and pharmacology focusing on concise rapid reporting of clinical or pre-clinical studies on a range of neuropsychiatric and neurological disorders. This journal is indexed on PubMed Central, the 'PsycINFO' database and CAS, and is the official journal of The International Neuropsychiatric Association (INA). The manuscript management system is completely online and includes a very quick and fair peer-review system, which is all easy to use. Visit http://www.dovepress.com/testimonials.php to read real quotes from published authors.

Submit your manuscript here: https://www.dovepress.com/neuropsychiatric-disease-and-treatment-journal 